\title{
Improvement the production of cytotoxic metabolites by Streptomyces griseus KJ623766
}

\author{
Ahmed S. Abu Zaid, Khaled M. Aboshanab", Mahmoud A. Yassien, and Nadia A. Hassouna \\ Department of Microbiology and Immunology, Faculty of Pharmacy, Ain Shams University, Cairo, Egypt
}

\begin{abstract}
The cell-free culture supernatant (CFCS) obtained from Streptomyces (S.) grisues (accession code KJ623766) fermentation, locally isolated Streptomyces strains from Egyptian soil sample, showed potent cytotoxic activity against $\mathrm{Caco} 2$ cell line. Fermentation was carried out in a $14 \mathrm{~L}$ laboratory fermenter, under optimum conditions of $28{ }^{\circ} \mathrm{C}, 200 \mathrm{rpm}, 5$ standard liters per minute (SLPM) aeration, 2 bar airflow pressure and uncontrolled pH. After 72 $\mathrm{h}$ of incubation, the cell-free culture supernatant (CFCS) was collected and extracted using ethyl acetate (1:1, v/v) at pH 7.0. Using 3-(4,5-dimethylthazol-2-yl)-2,5-diphenyl tetrazolium-bromide (MTT) assay, the ethyl acetate extract showed potential cytotoxic activity against $\mathrm{Caco} 2$ with $\mathrm{CD}_{50}$ of $14 \mu \mathrm{g} / \mathrm{mL}$. This showed an increase in cytotoxic activity by about 1.6 folds when compared to results obtained from shake flask $\left(\mathrm{CD}_{50} 22 \mu \mathrm{g} / \mathrm{mL}\right)$. Production improvement of cytotoxic activity was carried out also by genetic manipulation using a dose of 4 KiloGray (KGy) of gamma radiation. Fifteen out of forty-seven mutants showed higher potential cytotoxic activities when compared to that of the wild-type strain of S.griseus KJ623766. Mutants G31, G44, and G45 showed the most potent cytotoxic activities where they exhibited about 7 folds increase in potential cytotoxic activity with $\mathrm{CD}_{50}$ of $3.2 \pm 0.2,2.9 \pm 0.1$ and $3.25 \pm 0.43 \mu \mathrm{g} / \mathrm{mL}$, respectively.
\end{abstract}

Keywords: Bioassay-guided fractionation; cytotoxic activity; Fermentation; Streptomyces griseues; genetic manipulation; gamma radiation.

*Correspondence | Khaled M. Aboshanab; Professor of Microbiology and Immunology, Faculty of Pharmacy, Ain Shams University, African union organization street Abassia, 11566, Cairo, Egypt. Email: aboshanab2012@pharma.asu.edu.eg

Citation | Ahmed S. Abu Zaid, Khaled M. Aboshanab, Mahmoud A. Yassien, and Nadia A. Hassouna. 2017. Improvement the production of cytotoxic metabolites by Streptomyces griseus KJ623766. Arch Pharm Sci ASU 1(2): 31-38

DOI: $10.21608 /$ aps.2017.11022

Online ISSN: 2356-8380. Print ISSN: 2356-8399.

Received 27 August 2017. Accepted 11 October 2017.

Copyright: ${ }^{\circledR} 2017$ Abu Zaid et al. This is an open-access article licensed under a Creative Commons Attribution 4.0 International License (CC BY 4.0), which permits unrestricted use, distribution, and reproduction in any medium, provided the original author(s) and source are credited. Published by: Ain Shams University, Faculty of Pharmacy.

\section{INTRODUCTION}

Cancer diseases are a major health problem in both developed and developing countries [1]. Its complexity is due to; it is not only caused by the abnormal growth of cells with the potentiality to invade different organs but also by an impaired differentiation [2]. The World Health Organization (WHO) reports that every year there are approximately 38 million new cases of noncommunicable diseases (NCD) with cancer representing the second cause of NCD with 8.2 million deaths, corresponding to $22 \%$ of all NCD in 2012 [3]. Colorectal cancer is the second highest cause of cancer occurrence and death for men and women in the United States combined. An estimated 141210 cases were diagnosed in 2011 [4].

Natural products have been the mainstay of cancer chemotherapy for the past 30 years as; there is a strong urgency to find new therapeutic strategies for the treatment of cancers, especially for those that show drug-resistance, high risk of relapse, unavailability and / or poor therapeutic strategies. For this reason, much attention is paid 
to the therapeutic use of natural products, due to their high efficacy and low adverse effects [5]. These natural products include chemotherapeutic agents from plant, marine and bacterial sources[6].

Microorganisms have been the principal source of antibacterial agents and also provided some of the key drugs for cancer chemotherapy. To date, numerous bioactive compounds with profound impact on society have been reported from the genus Streptomyces whereby over 7000 bioactive compounds with diverse bioactivities including antimicrobial, antioxidant, anticancer and antifungal properties are identified from Streptomyces [7].

Bleomycin (Blenoxane), dactinomycin, mitomycin $\mathrm{C}$, and the anthracyclinones daunomycin and doxorubicin (Adriamycin) are notable drugs originating from Streptomycetes and used for cancer chemotherapy. All of these were introduced to the clinic before their modes of action had been determined [8].

Intensive approaches aimed at searching for more selective and novel structural agents have started to overcome the secondary effects of these compounds. so tissue culture microtiter-plate based screens were developed for the screening of novel microorganisms producing antitumor or cytotoxic agents [9]. Accordingly, this study aimed at the production of cytotoxic agents by $S$. griseus KJ623766 in shake flask, followed by extraction and determination of cytotoxic activity against $\mathrm{Caco} 2$ cell line. Production improvement of cytotoxic activity by the recovered soil Streptomyces strain was carried out using; largescale production in a laboratory fermenter and genetic manipulation by mutation using gamma radiation.

\section{MATERIALS AND METHODS}

\subsection{Microorganisms}

Locally isolated Streptomyces strain from Egyptian soil sample, S. griseus KJ623766, identified using $16 \mathrm{~S}$ ribosomal RNA gene sequences (GenBank database submission access code KJ623766). The purified colonies of
Streptomyces were stored onto starch nitrate agar slants slant (soluble starch $10 \mathrm{gm}, \mathrm{KNO}_{3} 2 \mathrm{gm}$, $\mathrm{K}_{2} \mathrm{HPO}_{4} 1 \mathrm{gm}, \mathrm{NaCl} 0.5 \mathrm{gm}, \mathrm{MgSO}_{4} .7 \mathrm{H}_{2} \mathrm{O} 0.5$ gm, $\mathrm{CaCO}_{3} 3 \mathrm{gm}$, agar $20 \mathrm{gm}, \mathrm{FeSO}_{4} .7 \mathrm{H}_{2} \mathrm{O} 0.1$ gm, $\mathrm{MnCl}_{2} 4 \mathrm{H}_{2} \mathrm{O} 0.1 \mathrm{gm}, \mathrm{ZnSO}_{4} 7 \mathrm{H}_{2} \mathrm{O} 0.1 \mathrm{gm}$ per 1liter of distilled water) and subcultured every month on the same medium.

For long-term preservation, the isolate was plated on the surface of starch nitrate agar for seven days of incubation at $28{ }^{\circ} \mathrm{C}$. After incubation, the formed spores were scalped off, suspended in a stock medium (tryptone $10 \mathrm{gm}$, yeast extract $5 \mathrm{gm}$, glycerine $500 \mathrm{ml}$ and distilled $\mathrm{H}_{2} \mathrm{O}$ to $1 \mathrm{~L}$ ) and stored at $-20{ }^{\circ} \mathrm{C}$

\subsection{Cell line}

Two cell lines were used, Kidney epithelial cells derived from the African green monkey (Vero cell line, ATCC No.CCL-81), Colorectal adenocarcinoma derived from human colon ( Caco 2 cell line). These cell lines were obtained from VACSERA, Egypt.

Caco-2 cell line was grown in T-75 tissue culture flasks containing $20 \mathrm{~mL}$ of RPMI-1640 medium with $1 \%$ antibiotic-antimycotic solution and $10 \%$ fetal bovine serum. The medium was changed at 48-h intervals and cells dissociated with trypsin solution $(0.25 \%$ in phosphate buffer saline). Vero cell line was propagated in Eagle minimum essential medium (EMEM) with Earl's balanced salt solution [10], supplemented with $10 \%$ Fetal bovine serum (FBS) and antibiotics (100 IU penicillin and $100 \mathrm{IU}$ streptomycin $/ \mathrm{ml}$ ) solution every $48 \mathrm{~h}$, and maintained in EMEM with Earl's balanced salt solution (EBSS) supplemented with $2 \%$ FBS and antibiotics solution.

\subsection{Production of cytotoxic agent(s) by $S$. griseus KJ623766}

\subsubsection{Preparation of seed culture}

From stock culture medium, an aliquot was spread on the surface of the starch nitrate agar plate, incubated for seven days at $28{ }^{\circ} \mathrm{C}$. After incubation, spores were scalped from the agar surface and suspended in $5 \mathrm{~mL}$ of distilled water. After homogenization, $2 \mathrm{~mL}$ of the resulting 
spore bacterial suspension was used to inoculate $100 \mathrm{~mL}$ of soybean meal broth (soybean $15 \mathrm{gm}$, glucose $15 \mathrm{gm}, \mathrm{NaCl} 5 \mathrm{gm}, \mathrm{CaCO}_{3} 1 \mathrm{gm}$ per $1 \mathrm{~L}$ of distilled water in $100 \mathrm{~mL}$ flask) $(2 \% \mathrm{v} / \mathrm{v})$ contained in $1 \mathrm{~L}$ flask. The flask was then incubated at $28{ }^{\circ} \mathrm{C}$ and $200 \mathrm{rpm}$ for $72 \mathrm{~h}$. The culture obtained (seed culture) was used to inoculate the production medium [11].

\subsubsection{Production of cytotoxic agent(s) in shake flasks}

An aliquot $(50 \mathrm{~mL})$ of seed culture obtained was used to inoculate $250 \mathrm{~mL}$ of soybean meal broth contained in $2 \mathrm{~L}$ flask. The inoculated flask was then incubated at $28{ }^{\circ} \mathrm{C}$ and $200 \mathrm{rpm}$ for 72 h. the culture obtained was centrifuged at 6000 RPM for $10 \mathrm{~min}$ using EBA20 Centrifuge (Hettrich, Germany) and the cell-free culture supernatant (CFCS) obtained was collected [11].

\subsection{Extraction}

About $250 \mathrm{~mL}$ of the CFCS was extracted with ethyl acetate at the level of $1: 1(\mathrm{v} / \mathrm{v})$ in a subsequent manner [12] and the collected organic layers were evaporated using rotavapor (Heidolph instruments $\mathrm{GmbH}$ and Co. Schwabach, Germany) under vacuum at $45{ }^{\circ} \mathrm{C}$. After complete evaporation, a sample of the fraction residue was redissolved in $1.25 \%$ DMSO in tissue culture medium. The cytotoxic activity of the redissolved fraction was evaluated against Caco2 using MTT assay.

\subsection{Production improvement of the cytotoxic activity of tested isolate}

\subsubsection{Fermentation in a laboratory fermenter}

The fermentation process was carried out in 14 L CelliGen 310 bioreactor (New Brunswick Scientific, Edison, NJ, USA) with 5 L working volume of soybean meal medium. After inoculation of the fermentation medium with the prepared seed culture $(5 \% \mathrm{v} / \mathrm{v})$, the fermentation condition was adjusted at $28{ }^{\circ} \mathrm{C}$ incubation temperature; $200 \mathrm{rpm}$ agitation speed, initial $\mathrm{pH}$ 7, 3 i.e 15 SLPM aeration rate and 2 bar airflow pressure. The dissolved oxygen concentration was adjusted to obtain $100 \%$ saturation at the beginning of the run and dissolved oxygen (DO) percentage was sensed by the DO probe and monitored during the fermentation process. The fermentation process was left for $72 \mathrm{~h}$ during which foam was suppressed using silicon oil. The culture obtained was centrifuged at 6000 RPM for $10 \mathrm{~min}$ using EBA20 Centrifuge (Hettrich, Germany) and the cell-free culture supernatant (CFCS) obtained was collected. The CFCS was extracted with ethyl acetate at the level of 1:1 $(\mathrm{v} / \mathrm{v})$ in the subsequent manner [12] and the collected organic layers were evaporated using rotavapor (Heidolph instruments $\mathrm{GmbH}$ and $\mathrm{Co}$. Schwabach, Germany) under vacuum at $45{ }^{\circ} \mathrm{C}$. After complete evaporation, a sample of the fraction residue was redissolved in $1.25 \%$ DMSO in tissue culture medium. The cytotoxic activity of the redissolved fraction was evaluated against Caco2 using MTT assay.

\subsubsection{Mutagenesis by treatment with gamma radiation}

Mutagenesis by treatment with gamma radiation was carried out according to Khaliq et al. [13] with some modifications; Streptomyces isolate was cultured in soybean meal broth at 28 ${ }^{\circ} \mathrm{C}, 200 \mathrm{rpm}$ for $72 \mathrm{~h}$ to yield a count of $10^{7}$ $\mathrm{CFU} / \mathrm{mL}$ (determined using viable count technique). About $5 \mathrm{ml}$ aliquots of the three days aged culture, contained in $20 \mathrm{~mL}$ transparent sterile glass vials, were exposed to increasing doses of gamma-irradiation ( 3,4 and $5 \mathrm{kGy}$ ) inside the irradiation chamber of gamma cell 220 equipment (National Center for Radiation Researches and Technology, Atomic Energy Authority, Nasr City, Cairo, Egypt). A ${ }^{60} \mathrm{Co}$ source from Indian gamma cell that provides a dose rate of $1.43 \mathrm{KGy} / \mathrm{h}$ at the time of the experiment was used as $a$ radiation source.

The dose of $4 \mathrm{KGy}$ gamma radiation resulted in $3 \log$ kill $(99.9 \%)$ as determined by counting the survivors [14]. After mutagenesis, the irradiated cell suspension was suitably diluted, plated on starch nitrate agar and incubated at 28 ${ }^{\circ} \mathrm{C}$ for 7 days. The resultant colonies were 
randomly selected, isolated and purified on starch nitrate slants. The isolated colonies obtained after exposure to gamma radiation were screened for their productivities of cytotoxic agents using 25 $\mathrm{mL}$ soybean meal medium contained in $250 \mathrm{~mL}$ shake flasks and under optimum conditions of fermentation $\left(28{ }^{\circ} \mathrm{C}, 200 \mathrm{RPM}\right.$ and $2 \% \mathrm{v} / \mathrm{v}$ inoculum size from seed culture for $72 \mathrm{~h}$ ).

After fermentation, the CFCS was extracted using an equal volume of ethyl acetate as described before, the organic layer evaporated under vacuum at $45{ }^{\circ} \mathrm{C}$. The residue obtained was tested for cytotoxic activity against $\mathrm{Caco} 2$ cell line, from which the $\mathrm{CD}_{50}$ of each mutant was determined and compared to that of the wild-type Streptomyces strain.

\subsection{Statistical analysis}

MTT assay measurements for all mutants that showed higher potential cytotoxic activities than wild-type strain were conducted in triplicates, thus, the results reported in this part represent respective average values \pm standard deviation. Data sets were analyzed using Graph Pad program (Graph Pad Software Inc., USA).

\subsection{Cytotoxicity assay using MTT method}

MTT assay was carried out as described by Saliba et al. [15] with some modifications; 100 $\mu \mathrm{L}$ of the crude extract (1mg in 5\% DMSO and tissue culture medium) was added to the well that contains $100 \mu \mathrm{L}$ of tissue culture medium, followed by two-fold serial dilution. Twelve dilutions were used for each crude extract to calculate $\mathrm{CD}_{50}$ for each. Control wells contained two aliquots of $100 \mu \mathrm{L}$ of ethyl acetate extract of soybean meal medium (1 mg dissolved in 5\% DMSO and tissue culture medium) and $100 \mu \mathrm{L}$ of tissue culture medium, followed by two-fold serial dilutions.

After $24 \mathrm{~h}$ incubation period at $37{ }^{\circ} \mathrm{C}$ in the $\mathrm{CO}_{2}$ incubator, wells were washed with PBS, followed by incubation with $100 \mu \mathrm{L}$ MTT solution $(1 \mathrm{mg} / \mathrm{mL})$ per each well for $1 \mathrm{~h}$ at 37 ${ }^{\circ} \mathrm{C}$. Supernatants were then removed by decantation and the cells were treated with 100 $\mu \mathrm{L}$ DMSO per each well to dissolve formazan crystals formed in the viable metabolically active cells. Elutes of the 12 wells of each tested crude extract were collected and their absorbance was measured at $540 \mathrm{~nm}$ using a different wavelength of $630 \mathrm{~nm}$ using Plato's R496 Microplate reader AMD diagnostics, Graz, Austria. Control wells were similarly treated. The percentage of cytotoxicity was calculated by the following formula [16].

Cytotoxicity $\%=1-\left\{\mathrm{A}_{540}\right.$ of test culture $/ \mathrm{A}_{540}$ of control culture $\} \times 100$

\section{RESULTS AND DISCUSSION}

\subsection{Identification of the selected Streptomyces isolates}

The selected Streptomyces isolate previously identified in a study conducted in our lab, using 16S rRNA gene sequence analysis [17]. The alignment pattern and scores obtained accounts for $100 \%$ identity to S. griseus and its 16 S rRNA gene sequences were submitted to the GenBank database under accession code KJ623766.

\subsection{Preparation of crude extract of cytotoxic agents produced by the tested isolate}

\subsubsection{Production of cytotoxic agents by the tested isolate}

The fermentation process was carried out in a $2 \mathrm{~L}$ shake flask as described before. After three days incubation period, the culture $(250 \mathrm{ml})$ was collected, centrifuged at $6000 \mathrm{rpm}$ for $10 \mathrm{~min}$. The collected supernatant (reddish brown color) was evaluated for cytotoxic activity and results showed promising cytotoxic activity (data not shown).

\subsubsection{Large-scale production of cytotoxic agents by the tested isolates}

The fermentation process was carried out using $14 \mathrm{~L}$ fermenter as described before. After three days incubation period, the culture $(2 \mathrm{~L})$ was collected from fermentor vessel, centrifuged at $6000 \mathrm{rpm}$ for $10 \mathrm{~min}$. The collected supernatant (reddish brown color) was evaluated 
for cytotoxic activity and results showed promising cytotoxic activity (data not shown).

\subsubsection{Extraction of cytotoxic agents from the CFCS}

Maskey et al. [18] studied the anti-cancer and antibacterial trioxacarcins with high anti-malaria activity from a marine streptomycete. They utilized ethyl acetate as an organic solvent for extraction of trioxacarcins from the fermentation broth of Streptomyces. Also, Ahmed et al. [19] extracted the antimicrobial agent isolated from Streptomyces violachromogenes (isolate no.YA118) using ethyl acetate at $\mathrm{pH} 3$.

Atta et al. [12] carried out their work for the biosynthesis of antifungal substance that demonstrated inhibitory effects against pathogenic fungi from Streptomyces albidoflavus, 143. The active metabolite was extracted using ethyl acetate $(1: 1, \mathrm{v} / \mathrm{v})$ at $\mathrm{pH}$ 7.0. In a previous study conducted in our lab, results obtained from extraction of the CFCS of $S$. griseus using different organic solvents, matched with all the previous results in the literature. Where ethyl acetate was shown as an excellent solvent for extraction of cytotoxic agents produced by the tested isolate at $\mathrm{pH}$ 7. Therefore in the present study extraction was done using ethyl acetate $(1: 1, \mathrm{v} / \mathrm{v})$ at $\mathrm{pH} 7.0$.

As described by Atta et al. (2011) [12], in brief; after the fermentation process, the CFCS was extracted by using Ethyl acetate at the level of $1: 1(\mathrm{v} / \mathrm{v})$ in a subsequent manner. The organic phase was collected and evaporated under reduced pressure using a rotary evaporator to yield a reddish-brown solid residue $(0.2 \mathrm{mg}$ for shake flasks and $1.5 \mathrm{~g}$ for laboratory fermenter). A sample of each fraction residue was redissolved in $1.25 \%$ DMSO in tissue culture medium to evaluate the cytotoxic activities against $\mathrm{Caco} 2$ cancer cell line and Vero cell line using MTT assay.

For shake flasks, the obtained results showed potent cytotoxic activity against $\mathrm{Caco} 2$ and Vero cell lines with $\mathrm{CD}_{50}$ of $22 \mu \mathrm{g} / \mathrm{mL}$ and $74 \mu \mathrm{g} / \mathrm{mL}$, respectively. In the case of laboratory fermenter, higher cytotoxic activities were observed with $\mathrm{CD}_{50}$ of $14 \mu \mathrm{g} / \mathrm{mL}$ and $68 \mu \mathrm{g} / \mathrm{mL}$, respectively (Fig. 1).

According to the screening program of American National Cancer Institute (NCI), a crude extract is generally considered to have in vitro cytotoxic activity if the $\mathrm{CD}_{50}$ value is $\leq$ $30 \mu \mathrm{g} / \mathrm{ml}$. Therefore; S. griseus KJ623766 ethyl acetate extract showed potential cytotoxic activities against $\mathrm{Caco} 2$ cell lines which indicate the presence of compounds with higher selectivity to human colorectal adenocarcinoma in the ethyl acetate extract. While weak cytotoxic activity against Vero cell line, non-tumourigenic when a cell passage was not prolonged [20]. These results indicate the presence of compounds with promising anticancer activity.

In bioprocesses, microorganisms are part of the chemistry, and they are susceptible to changes in the microorganism's living environment such as temperature, dissolved oxygen, $\mathrm{pH}$, and others. Both aeration and agitation were kept constant at $3 \mathrm{vvm}$ and 200 rpm, respectively during fermentation in laboratory fermenter, and played a significant role in increasing the productivity of the process; as both cannot be controlled in shake flask.

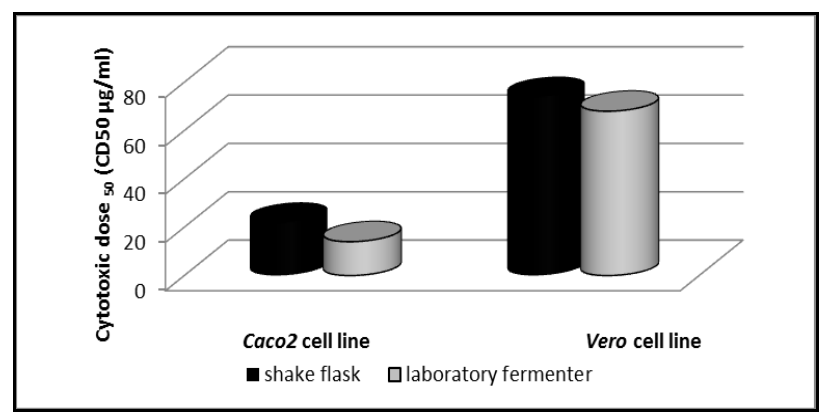

Fig. 1 potential cytotoxic activities of crude extracts obtained from S. griseus KJ623766 fermentation in shake flask and laboratory fermenter against $\mathrm{Caco} 2$ and Vero cell lines

\subsection{Improvement of the production of cytotoxic metabolites using gamma radiation}

Random mutagenesis and fermentation screening have been reported as an effective way 
to improve the productivity of industrial microbial cultures [21]. The most effective way to broaden the spectrum of base pair substitutions for yield improvement is to develop a protocol for AT-CG transversions. So far, no chemical mutagen has been reported that can induce AT to CG transversions [22]. However, AT-CG transversions were found in cells treated with ${ }^{60} \mathrm{Co}$ gamma rays [23]. So treatment with ${ }^{60} \mathrm{Co}$ gamma rays was used to improve the productivity of the cytotoxic metabolites by the studied isolate.

This was carried out by isolation of mutants resistant to $4 \mathrm{KGy}$ doses of gamma mutation, the dose that caused $99.99 \%$ kill. The collected colonies obtained after mutagenesis were screened for potential cytotoxic activities. As illustrated in table 1, the collected colonies exhibited lower, equal or higher cytotoxic activities as compared to that of the wild-type strain of each isolate. Results revealed that; about $32 \%$ of collected mutants showed an increase in potential cytotoxic activities.

Table 1 Screening of collected mutants of S.griseus KJ623766 for their potential cytotoxic activities

\begin{tabular}{|c|c|c|c|c|c|}
\hline \multirow{2}{*}{ Isolate } & \multirow{2}{*}{$\begin{array}{c}\text { No. of } \\
\text { collected } \\
\text { colonies }\end{array}$} & \multicolumn{2}{|c|}{$\begin{array}{c}\text { No. of colonies showing } \\
\text { potential cytotoxic } \\
\text { activities }\end{array}$} & $\begin{array}{c}\text { Percentage } \\
\text { of colonies } \\
\text { with } \\
\text { higher } \\
\text { cytotoxic } \\
\text { activities }\end{array}$ \\
\cline { 3 - 5 } & & lower & Equal & Higher & \\
\hline $\begin{array}{c}\text { S.griseus } \\
\text { KJ623766 }\end{array}$ & 47 & 22 & 10 & 15 & $32 \%$ \\
\hline
\end{tabular}

After mutagenesis, 47 colonies were randomly selected and mutants isolated were tested for potential cytotoxic activities against $\mathrm{CaCO} 2$ cell line using MTT assay.

Twenty-two mutants showed lower potential cytotoxic activities (Fig. 2); ten mutants exhibited no detectable changes in the potential cytotoxic activities (Fig. 3) and fifteen mutants showed higher potential cytotoxic activities (Fig. 4) when compared to that of the wild-type strain of S.griseus KJ623766.

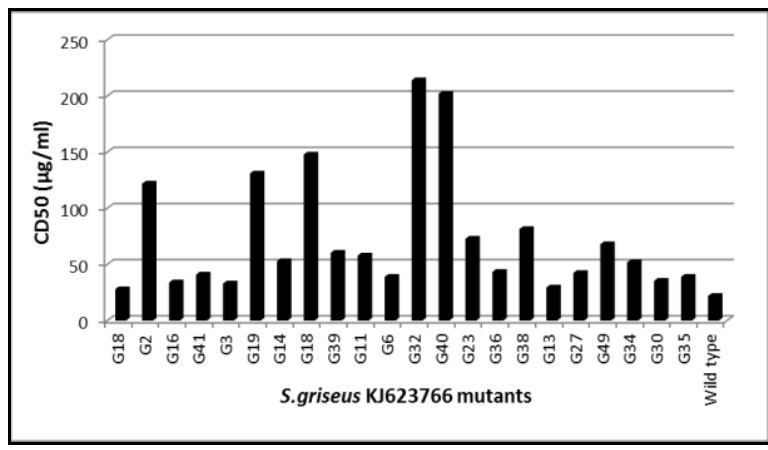

Fig 2 S.griseus KJ623766 mutants showed a decrease in potential cytotoxic activities against $\mathrm{CaCO} 2$ cell line when compared to that of the wild-type strain

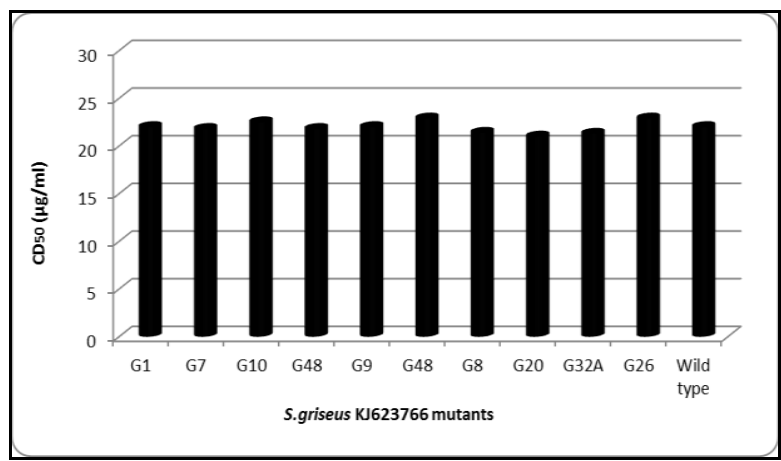

Fig 3 S.griseus KJ623766 mutants showed no detectable change in potential cytotoxic activities against $\mathrm{CaCO} 2$ cell line when compared to that of the wild-type strain

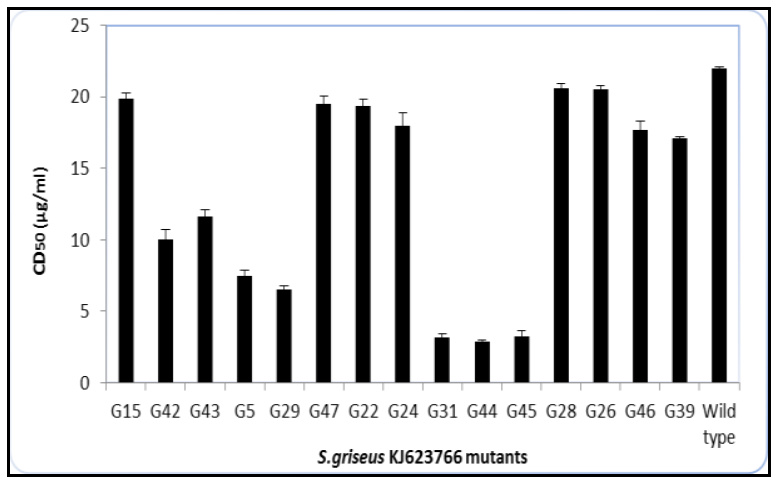

Fig 4 S.griseus KJ623766 mutants showed an increase in potential cytotoxic activities against $\mathrm{CaCO} 2$ cell line when compared to that of the wild-type strain

Results revealed that; mutants coded G2, G18, G19, G32 and G40 exhibited a dramatic reduction in cytotoxic activities (with $\mathrm{CD}_{50}$ of $122,148,131,214$ and $202 \mu \mathrm{g} / \mathrm{ml}$, respectively) when compared to that of the wild-type strain $\left(\mathrm{CD}_{50} 22 \mu \mathrm{g} / \mathrm{ml}\right)$. Mutants coded G42 and G43 
showed about 2 folds increases in potential cytotoxic activity with $\mathrm{CD}_{50}$ of $10.06 \pm 0.66$ and $11.6 \pm 0.51 \mu \mathrm{g} / \mathrm{ml}$, respectively. Mutants G5 and G29 exhibited about 3 folds increase in potential cytotoxic activities with $\mathrm{CD}_{50}$ of $7.46 \pm 0.44$ and $6.51 \pm 0.25 \mu \mathrm{g} / \mathrm{ml}$, respectively. Finally mutants G31, G44 and G45 showed most potent cytotoxic activities where they exhibited about 7 folds increase in potential cytotoxic activity with $\mathrm{CD}_{50}$ of $3.2 \pm 0.2,2.9 \pm 0.1$ and $3.25 \pm 0.43 \mu \mathrm{g} / \mathrm{ml}$, respectively. The fifteen isolates that showed an increase in potential cytotoxic activities were sub-classified into three groups; group showed potent increase in activity (G31,G44, and G45), group showed moderate increase in activity (G42, G43, G5 and G29) and group showed mild increase in activity (G15, G47, G22, G24, G28, G26, G46, and G39). One way analysis of variance (ANOVA) for these three groups and the wild-type strain showed a p-value of < 0.0001 , so results were considered extremely significant.

\section{Conclusion}

S. griseus KJ623766 CFCS contain metabolites with promising anticancer activity, as it showed high selectivity to human colorectal adenocarcinoma, while weak cytotoxic activity against Vero cell line was observed. Improvement of the production of the produced cytotoxic metabolites was achieved by largescale production in a laboratory fermenter as well as mutagenesis using gamma radiation. Further studies are required for isolation and structure elucidation of the cytotoxic metabolites produced by a wild-type strain of S. griseus KJ623766, as well as those produced by mutants showed an increase in potential cytotoxic activities.

\section{Acknowledgments}

Authors would like to express deepest thanks to "Center for Drug Discovery and Development Research, Faculty of Pharmacy, Ain-Shams University" for its support.

\section{REFERENCES}

1 Hernandez BY, Green MD, Cassel KD, Pobustsky AM, Vu V, Wilkens LR. Preview of
Hawaii cancer facts and figures 2010. Hawaii medical journal 2010; 69:223-224.

2 Gough NR: Focus issue: From genomic mutations to oncogenic pathways. Science Signalling 2014; 6:eg3.

3 Russo M, Russo GL, Daglia M, Kasi PD, Ravi S, Nabavi SF, et al. Understanding genistein in cancer: The "good" and the "bad" effects: A review. Food Chem 2016; 196:589-600.

4 Jennifer R, Robin V, Rebecca M. Effectively Communicating Colorectal Cancer Screening Information to Primary Care Providers. American Journal of Health Education 2012; 43:194-201.

5 Cragg GM, Newman DJ. Natural products: A continuing source of novel drug leads. Biochimica et Biophysica Acta (BBA)-General Subjects 2013; 1830:3670-3695.

6 Pettit GR, Pierson FH, Herald CL. Anticancer Drugs from Animals, Plants, and Microorganisms. Journal of Chemical Technology and Biotechnology 1996; 66:106.

7 Tan LT-H, Ser H-L, Yin W-F, Chan K-G, Lee L$\mathrm{H}$, Goh B-H. Investigation of Antioxidative and Anticancer Potentials of Streptomyces sp. MUM256 Isolated from Malaysia Mangrove Soil. Front Microbiol 2015; $6 . \quad$ DOI: 10.3389/fmicb.2015.01316

8 Mann J: Natural products in cancer chemotherapy: past, present, and future. Nat Rev Cancer 2002; 2:143-148.

9 Mirabelli CK, Bartus H, Bartus JOL, Johnson R, Mong SM, Sung SP, et al. Application of tissue culture microtitre test for the detection of cytotoxic agents from natural products. J Antibiot $1985 ; 38: 758-766$.

10 Eagle H. Amino acid metabolism in mammalian cell cultures. Science 1959; 130: 432--437.

11 Peng Y, Wang Y-H, Zhang S-L, Chu J, Zhuang Y-P, Wang M-L, et al. Isolation of soluble proteins from an industrial strain Streptomyces avermitilis in complex culture medium for twodimensional gel electrophoresis. Journal of microbiological methods 2008; 73:105-110.

12 Atta HM, El-Sehrawi MH, Bahobail AS. Antifungal Macrodiode Production By Streptomyces albidoflavus-143: Fermentation, Purification, and Biological Activities. Journal of American Science 2011; 7:13-22. 
13 Khaliq S, Akhtar K, Ghauri MA, Iqbal R, Khalid AM, Muddassar M. Change in colony morphology and kinetics of tylosin production after UV and gamma irradiation mutagenesis of Streptomyces fradiae NRRL-2702. Microbiological Research 2009; 164:469—477.

14 Raza ZA, Khan MS, Khaled ZM. Evaluation of distant carbon sources in biosurfactant production by a gamma ray-induced pseudomonas putida mutant. Process Biochemistry 2007; 42:686-692.

15 Saliba AM, Filloux A, Ball G, Silva ASV, Assis M-C, Plotkowski M-C. Type III secretionmediated killing of endothelial cells by Pseudomonas aeruginosa. Microbial Pathogenesis 2002; 33:153-166.

16 Murakami J, Kishi K, Hirai K, Hiramatsu K, Yamasaki T, Nasu M. Macrolides, and clindamycin suppress the release of Shiga-like toxins from Escherichia coli O157: H7 in vitro. International Journal of Antimicrobial Agents 2000; 15:103-109.

17 Kavitha A, Prabhakar P, Narasimhulu M, Vijayalakshmi M, Venkateswarlu Y, Rao KV, et al. Isolation, characterization and biological evaluation of bioactive metabolites from Nocardia levis MK-VL_113. Microbiol Res 2010;165:199_210.

18 Maskey RP, Helmke E, Kayser O, Fiebig HH, Maier A, Busche A, et al. Anti-cancer and antibacterial trioxacarcins with high anti-malaria activity from a marine Streptomycete and their absolute stereochemistry. J Antibiot 2004; 57:771-779.

19 Ahmed AA. Production of Antimicrobial Agent by Streptomyces violachromogenes. Saudi Journal of Biological Sciences 2007; 14:7-16.

20 Osada N, Kohara A, Yamaji T, Hirayama N, Kasai F, Sekizuka T, et al. The Genome Landscape of the African Green Monkey KidneyDerived Vero Cell Line. DNA Res 2014; 21:673683.

21 Parekh S, Vinci V, Strobel R. Improvement of microbial strains and fermentation processes. Appl Microbiol Biotechnol 2000; 54:287-301.

22 Baltz R: Genetic methods and strategies for secondary metabolite yield improvement in actinomycetes. Antonie Van Leeuwenhock 2001; 79:251-259.

23 Xie C, An X, Li J, Jian M, Jian Y, Zeng L.
Comparison of base substitutions in response to nitrogen ion implantation and 60Co gamma-ray irradiation in E. coli. Genet Mol Biol 2004; 27:284-290. 